\title{
PENERAPAN SISTEM ANTRIAN SEBAGAI UPAYA MENGOPTIMALKAN PELAYANAN REKONSILIASI BARANG MILIK NEGARA (BMN) DI KANTOR PELAYANAN KEKAYAAN NEGARA DAN LELANG PALU
}

\author{
D. Delfianti ${ }^{1}$, A. I. Jaya ${ }^{2}$, dan Resnawati ${ }^{3}$ \\ 1,2,3Program Studi Matematika Jurusan Matematika \\ Fakultas Matematika dan IImu Pengetahuan Alam Universitas Tadulako \\ Jalan Sukarno-Hatta Km. 9 Palu 94118, Indonesia \\ 1dian.delfianti@yahoo.co.id, 2jayaindraagus@gmail.com,3r35n4w4t1@yahoo.com
}

\begin{abstract}
The queue is an activity that arises because of the number of services the facility is less than the number who need the service. Kantor Pelayanan Kekayaan Negara dan lelang(KPKNL) Palu is one of the government agencies that implement a queuing system on reconciliation of State Owned Property (BMN) that it held every semester, where they just served the 337 of work units comparethe 700 of work unit within two weeks. This study aimed is to obtain the characteristics of the queue and the optimum number of servers in the service of reconciliation in KPKNL Palu using queues. The results showed the busiest time is on July 21,2016 . The addition of a server from 4 to 8 servers showed a decrease in the queue. It is perceptibly from a queue characteristics decrease in levels of activity server ( $\rho$ ) from $75 \%$ to $20,8 \%$, the number of work units waiting in the queue $(L q)$ of $1,53 \approx 2$ work units/ hour to 0 work unit/hour, the number of work units waiting in the system $(L s)$ of $4,53 \approx 5$ work units/hour into $1,667 \approx 2$ work units/hour, time waiting in queues $(W q)$ of 6,11 minutes to 0 minutes, the waiting time in the system (Ws) of 18,11 minutes to 6,667 minutes and the number of work units that is served in 2 weeks are 700 work units.
\end{abstract}

Keywords : Characteristics, Queue, Reconciliation of State Owned Property (BMN).

\section{ABSTRAK}

Antrian adalah suatu kegiatan yang timbul karena jumlah fasilitas pelayanan jasa lebih sedikit dibandingkan jumlah yang membutuhkan pelayanan. Kantor Pelayanan Kekayaan Negara dan Lelang (KPKNL) Palu merupakan salah satu instansi pemerintah yang menerapkan sistem antrian pada saat pelayanan rekonsiliasi Barang Milik Negara (BMN) dan dilaksanakan setiap akhir semester, dimana jumlah satker yang dilayani adalah 337 satker dari yang seharusnya dilayani sebanyak 700 satker dalam waktu 2 minggu. Penelitian ini bertujuan untuk mendapatkan karakteristik antrian dan jumlah server yang optimum dalam pelayanan rekonsiliasi di KPKNL Palu dengan menggunakan metode antrian. Hasil penelitian menunjukkan waktu tersibuk adalah pada tanggal 21 Juli 2016. Penambahan server dari 4 menjadi 8 server menunjukkan adanya penurunan antrian. Hal ini dapat dilihat dari karakteristik antrian penurunan tingkat kesibukan server $(\rho)$ dari $75 \%$ menjadi 20,8 \%, banyak satker yang 
menunggu dalam antrian $\left(L_{q}\right)$ dari $1,53 \approx 2$ satker/jam menjadi 0 satker/jam, banyak satker yang menunggu dalam sistem $\left(L_{s}\right)$ dari $4,53 \approx 5$ satker/jam menjadi 1,667 $\approx 2$ satker/jam, waktu menunggu dalam antrian $\left(W_{q}\right)$ dari 6,11 menit menjadi 0 menit, waktu menunggu dalam sistem $\left(W_{s}\right)$ dari 18,11 menit menjadi 6,667 menit dan total satker yang terlayani selama 2 minggu adalah 700 satker.

Kata kunci : Karakteristik, Antrian, Rekonsiliasi Barang Milik Negara (BMN).

\section{PENDAHULUAN}

Pada zaman modern sekarang ini semua dituntut serba cepat. Hal ini dikarenakan semakin bertambahnya jumlah populasi penduduk didunia, perkembangan teknologi dan pembangunan yang ada di segala bidang juga berlangsung dengan cepat. Suatu perusahaan dibidang jasa maupun manufaktur harus mampu memberikan pelayanan yang cepat serta terbaik sesuai dengan keinginan pelanggan untuk memenuhi kebutuhannya mengingat akan jumlah populasi yang banyak tersebut. Jasa merupakan sektor ekonomi yang berkembang secara cepat dan jasa merupakan sektor ekonomi terbesar dalam masyarakat maju (Heizer, 2004).

Perusahaan atau organisasi sangat memerlukan manajemen operasional dalam menjalankan kegiatan usahanya. Hal ini diperlukan untuk memperbaiki kinerja produktivitasnya sehingga akan mendapatkan keputusan yang efektif bagi perusahaan atau organisasi di mata pelanggannya. Salah satu masalah yang perlu diperhatikan dalam kegiatan usaha adalah masalah antrian. Pemakaian waktu seminim mungkin dalam antrian merupakan hal yang penting untuk diperhatikan oleh setap penyedia jasa layanan.

Salah satu tempat terjadinya kasus antrian yaitu pada aktifitas pelayanan rekonsiliasi Barang Milik Negara (BMN) yang dilakukan setiap akhir semester di Kantor Pelayanan Kekayaan Negara dan Lelang Palu. Mencegah timbulnya antrian atau mengurangi antrian yang panjang adalah dengan menganalisis sistem antrian pelayanan rekonsiliasi Barang Milik Negara(BMN) dengan menerapkan teori antrian untuk mengetahui karakteristik antrian pelayanan rekonsiliasi Barang Milik Negara(BMN) yang dilaksanakan di Kantor Pelayanan Kekayaan Negara dan Lelang Palu.

\section{METODE PENELITIAN}

1. Mempersiapkan penelitian.

2. Mengkaji literatur tentang teori antrian, jenis antrian dan model antrian

3. Mengumpulkan data berupa data kedatangan, data pelayanan, dan data jalur yang terbuka.

4. Membangun model antrian Multi Channel Single Phase.

5. Uji kedatangan dan waktu pelayanan dengan menggunakan uji Kolmogorov Smirnov

6. Menentukan karakteristik antrian dengan rumus antrian M/M/S (Multiple Channel Query System)

7. Menarik kesimpulan dari hasil penelitian. 


\section{HASIL DAN PEMBAHASAN}

\subsection{Analisis data}

Untuk proses analisa data yang digunakan peneliti yaitu dengan menggunakan uji kolmogorov smirnov satu sampel. Pola kedatangan akan diuji apakah berdistribusi poisson atau tidak dan waktu pelayanan diuji apakah berdistribusi eksponensial atau tidak dengan mengunakan program SPSS 12.0 for windows dengan langkah-langkah:

1. Hipotesis pengujian:

$\mathrm{H}_{0}: \mu$ : Pola kedatangan satker berdistribusi Poisson

$\mathrm{H}_{1}: \mu$ : Pola kedatangan satker tidak berdistribusi Poisson

$\mathrm{H}_{0}: \mu$ : Waktu pelayanan satker berdistribusi Eksponensial

$\mathrm{H}_{1}: \mu$ : Waktu pelayanan tidak berdistribusi Eksponensial

2. Adapun rumus Kolmogorov Smirnov yang digunakan dalam penelitian ini adalah

$\mathrm{D}=\operatorname{Maks}\left|\mathrm{F}_{\mathrm{a}}(\mathrm{x})-\mathrm{F}_{\mathrm{e}}(\mathrm{x})\right|$

3. Taraf signifikan $5 \%$ atau 0,05

4. Kriteria pengujian

$\mathrm{H}_{0}$ diterima apabila Kolmogorov Smirnov Hitung $\leq$ Kolmogorov Smirnov Tabel.

$\mathrm{H}_{0}$ ditolak apabila Kolmogorov Smirnov Hitung $>$ Kolmogorov Smirnov Tabel.

Tabel 1 : Hasil Uji Kecocokan Distribusi Pola Kedatangan

One-Sample Kolmogorov-Smirnov Test

\begin{tabular}{|ll|r|}
\hline & & Kedatangan \\
\hline $\mathrm{N}$ & & 10 \\
Poisson Parameter & & \\
Most Extreme Differences & Mean & 9.7000 \\
& Absolute & .248 \\
& Positive & .181 \\
& Negative & -.248 \\
Kolmogorov-Smirnov Z & & .786 \\
Asymp. Sig. (2-tailed) & & .568 \\
\hline
\end{tabular}

a. Test distribution is Poisson.

b. Calculated from data.

Tabel 2 : Hasil Uji Kecocokan Distribusi Waktu Pelayanan

One-Sample Kolmogorov-Smirnov Test

\begin{tabular}{|ll|r|}
\hline & & VAR00001 \\
\hline $\mathrm{N}$ & & 10 \\
Exponential parameter. ${ }^{\mathrm{a}, \mathrm{b}}$ & Mean & 14.3500 \\
Most Extreme Differences & Absolute & .407 \\
& Positive & .248 \\
& Negative & -.407 \\
Kolmogorov-Smirnov $\mathrm{Z}$ & & 1.287 \\
Asymp. Sig. (2-tailed) & & .073 \\
\hline
\end{tabular}

a. Test Distribution is Exponential.

b. Calculated from data. 
a) Dari Tabel 1 hasil pengujian diperoleh nilai simpangan positif $\left(D^{+}\right)$adalah 0,181 dan simpangan negatifnya sebesar $-0,248$ sehingga nilai statistik uji Uji Kolmogorov Smirnov satu sampel adalah simpangan terbesar (absolute) yaitu 0,248 dan nilai peluangnya adalah 0,568. Karena nilai peluangnya lebih besar dari taraf signifikan 0,05 maka dapat disimpulkan $\mathrm{H}_{0}$ diterima yang artinya bahwa pola kedatangan mengikuti distribusi Poisson.

b) Dari Tabel 2 hasil pengujian diperoleh nilai simpangan positif $\left(D^{+}\right)$adalah 0,248 dan simpangan negatifnya sebesar $-0,407$ sehingga nilai statistik uji Uji Kolmogorov Smirnov satu sampel adalah simpangan terbesar (absolute) yaitu 0,407 dan nilai peluangnya adalah 0,073. Karena nilai peluangnya lebih besar dari taraf signifikan 0,05 maka dapat disimpulkan $\mathrm{H}_{0}$ diterima yang artinya bahwa waktu pelayanan mengikuti distribusi Eksponensial.

\subsection{Analisis Model Antrian Yang Diteliti}

Tabel 3 : Data Kedatangan Satker

\begin{tabular}{|c|c|c|c|c|c|c|c|c|c|c|}
\hline \multirow[b]{2}{*}{$\begin{array}{c}\text { Waktu } \\
\text { Pengamata } \\
\text { n }\end{array}$} & \multicolumn{8}{|c|}{ Jam Kerja } & \multirow[b]{2}{*}{$\begin{array}{l}\text { Total } \\
\text { (per } \\
\text { hari) }\end{array}$} & \multirow{2}{*}{$\begin{array}{c}\text { Rata- } \\
\text { rata(p } \\
\text { er } \\
\text { jam })\end{array}$} \\
\hline & $\begin{array}{c}08.00 \\
- \\
09.00\end{array}$ & $\begin{array}{c}09.00 \\
- \\
10.00\end{array}$ & $\begin{array}{c}10.00 \\
- \\
11.00\end{array}$ & $\begin{array}{c}11.00 \\
- \\
12.00\end{array}$ & $\begin{array}{c}13.00 \\
- \\
14.00\end{array}$ & $\begin{array}{c}14.00 \\
- \\
15.00\end{array}$ & $\begin{array}{c}15.00 \\
- \\
16.00\end{array}$ & $\begin{array}{c}16.00 \\
- \\
17.00\end{array}$ & & \\
\hline $\begin{array}{c}\text { Senin, } \\
11 / 07 / 2016\end{array}$ & 5 & 6 & 5 & 8 & 9 & 4 & 5 & 3 & 45 & 6 \\
\hline $\begin{array}{c}\text { Selasa, } \\
\text { 12/07/2016 }\end{array}$ & 3 & 5 & 7 & 4 & 6 & 7 & 6 & 5 & 43 & 6 \\
\hline $\begin{array}{c}\text { Rabu, } \\
13 / 07 / 2016\end{array}$ & 5 & 4 & 5 & 9 & 10 & 9 & 8 & 7 & 57 & 8 \\
\hline $\begin{array}{c}\text { Kamis, } \\
14 / 07 / 2016\end{array}$ & 6 & 8 & 9 & 8 & 7 & 7 & 6 & 4 & 55 & 7 \\
\hline $\begin{array}{c}\text { Jumat, } \\
15 / 07 / 2016\end{array}$ & 6 & 6 & 7 & 10 & 7 & 7 & 8 & 8 & 59 & 8 \\
\hline $\begin{array}{c}\text { Senin, } \\
18 / 07 / 2016\end{array}$ & 9 & 10 & 13 & 9 & 11 & 10 & 8 & 8 & 78 & 10 \\
\hline $\begin{array}{c}\text { Selasa, } \\
\text { 19/07/2016 }\end{array}$ & 7 & 7 & 10 & 14 & 12 & 8 & 9 & 8 & 75 & 10 \\
\hline $\begin{array}{c}\text { Rabu, } \\
20 / 07 / 2016\end{array}$ & 9 & 12 & 16 & 10 & 15 & 14 & 11 & 10 & 97 & 13 \\
\hline $\begin{array}{c}\text { Kamis, } \\
21 / 07 / 2016\end{array}$ & 10 & 15 & 14 & 18 & 16 & 13 & 14 & 15 & 115 & 15 \\
\hline $\begin{array}{c}\text { Jumat, } \\
22 / 07 / 2016\end{array}$ & 10 & 14 & 13 & 15 & 16 & 15 & 14 & 13 & 110 & 14 \\
\hline
\end{tabular}


Tabel 4 : Data Pelayanan Satker

\begin{tabular}{|c|c|c|c|c|c|c|c|c|c|c|}
\hline \multirow{2}{*}{$\begin{array}{c}\text { Waktu } \\
\text { Pengamata } \\
n\end{array}$} & \multicolumn{8}{|c|}{ Jam Kerja } & \multirow{2}{*}{$\begin{array}{l}\text { Total } \\
\text { (per } \\
\text { hari) }\end{array}$} & \multirow{2}{*}{$\begin{array}{l}\text { Rata- } \\
\text { rata(p } \\
\text { er } \\
\text { jam })\end{array}$} \\
\hline & $\begin{array}{c}08.00 \\
- \\
09.00\end{array}$ & $\begin{array}{c}09.00 \\
- \\
10.00\end{array}$ & $\begin{array}{c}10.00 \\
- \\
11.00\end{array}$ & $\begin{array}{c}11.00 \\
- \\
12.00\end{array}$ & $\begin{array}{c}13.00 \\
- \\
14.00\end{array}$ & $\begin{array}{c}14.00 \\
- \\
15.00\end{array}$ & $\begin{array}{c}15.00 \\
- \\
16.00\end{array}$ & $\begin{array}{c}16.00 \\
- \\
17.00\end{array}$ & & \\
\hline $\begin{array}{c}\text { Senin, } \\
11 / 07 / 2016\end{array}$ & 5 & 5 & 3 & 3 & 5 & 3 & 6 & 4 & 34 & 5 \\
\hline $\begin{array}{c}\text { Selasa, } \\
\text { 12/07/2016 }\end{array}$ & 3 & 5 & 2 & 7 & 4 & 6 & 5 & 4 & 36 & 5 \\
\hline $\begin{array}{c}\text { Rabu, } \\
13 / 07 / 2016\end{array}$ & 5 & 4 & 4 & 6 & 4 & 3 & 3 & 4 & 33 & 5 \\
\hline $\begin{array}{c}\text { Kamis, } \\
14 / 07 / 2016\end{array}$ & 6 & 4 & 4 & 3 & 2 & 3 & 3 & 4 & 29 & 4 \\
\hline $\begin{array}{c}\text { Jumat, } \\
15 / 07 / 2016\end{array}$ & 5 & 2 & 4 & 3 & 2 & 4 & 4 & 5 & 29 & 4 \\
\hline $\begin{array}{c}\text { Senin, } \\
18 / 07 / 2016\end{array}$ & 6 & 4 & 5 & 3 & 3 & 3 & 4 & 5 & 33 & 5 \\
\hline $\begin{array}{c}\text { Selasa, } \\
\text { 19/07/2016 }\end{array}$ & 6 & 4 & 3 & 4 & 3 & 3 & 4 & 4 & 31 & 4 \\
\hline $\begin{array}{c}\text { Rabu, } \\
20 / 07 / 2016\end{array}$ & 6 & 4 & 3 & 4 & 5 & 3 & 4 & 3 & 32 & 4 \\
\hline $\begin{array}{c}\text { Kamis, } \\
21 / 07 / 2016\end{array}$ & 5 & 4 & 4 & 3 & 4 & 4 & 4 & 5 & 33 & 5 \\
\hline $\begin{array}{c}\text { Jumat, } \\
\text { 22/07/2016 }\end{array}$ & 8 & 6 & 5 & 5 & 4 & 3 & 5 & 3 & 39 & 5 \\
\hline & & & al satker & lang ter & yani & & & & 337 & atker \\
\hline
\end{tabular}

Dari Tabel 4 terlihat banyak satker yang terlayani hanya sebanyak 337 satker dari yang seharusnya 700 satker. Berikut hasil hitung karakteristik antrian dari hasil pengamatan.

Tabel 5 : Hasil hitung karakteristik antrian

\begin{tabular}{|c|c|c|c|c|c|c|c|c|}
\hline Waktu Pengamatan & $\Lambda$ & $\mathrm{M}$ & $\mathrm{M}$ & $\begin{array}{c}\rho \\
(\%)\end{array}$ & $\begin{array}{c}\mathrm{Lq} \\
\text { (satker) }\end{array}$ & $\begin{array}{c}\text { Ls } \\
\text { (satker) }\end{array}$ & $\begin{array}{c}\text { Wq } \\
\text { (menit) }\end{array}$ & $\begin{array}{c}\text { Ws } \\
\text { (menit) }\end{array}$ \\
\hline Senin, 11/07/2016 & 6 & 5 & 4 & 30 & 0,02 & 1,22 & 0,16 & 12,16 \\
\hline Selasa, 12/07/2016 & 6 & 5 & 4 & 30 & 0,02 & 1,22 & 0,16 & 12,16 \\
\hline Rabu, 13/07/2016 & 8 & 5 & 4 & 40 & 0,06 & 1,66 & 0,45 & 12,45 \\
\hline Kamis, 14/07/2016 & 7 & 4 & 4 & 44 & 0,09 & 1,84 & 0,79 & 15,79 \\
\hline Jumat, 15/07/2016 & 8 & 4 & 4 & 50 & 0,17 & 2,17 & 1,3 & 16,3 \\
\hline Senin, 18/07/2016 & 10 & 5 & 4 & 50 & 0,17 & 2,17 & 1,043 & 13,043 \\
\hline Selasa, 19/07/2016 & 10 & 4 & 4 & 63 & 0,53 & 3,03 & 3,2 & 18,2 \\
\hline Rabu, 20/07/2016 & 13 & 5 & 4 & 65 & 0,66 & 3,26 & 3,04 & 15,04 \\
\hline Kamis, 21/07/2016 & 15 & 5 & 4 & 75 & 1,53 & 4,53 & 6,11 & 18,11 \\
\hline Jumat, 22/07/2016 & 13 & 5 & 4 & 65 & 0,66 & 3,26 & 3 & 15 \\
\hline
\end{tabular}




\subsection{Analisis Model Antrian Dengan Melakukan Penambahan Server}

Setelah mengamati model antrian pada pelayanan rekonsiliasi didapatkan karakteristik antrian yang menunjukan tingkat kesibukan server tidak tentu setiap harinya, para satker yang terlayani hanya sebanyak 337 satker dari yang seharusnya 700 satker. Berdasarkan SOP (Standar Operasional Prosedur) yang ditetapkan Kantor Pelayanan Kekayaan Negara dan Lelang Palu seharusnya pelayanan rekonsiliasi dilakukan selama 2 minggu yaitu tanggal 11 juli-22 juli 2016 yang berarti bahwa nilai efektif pelayanannya adalah harus melayani minimal 70 satker/hari dengan waktu pelayanan per satker $(W s)$ selama 6,85 menit/satker. Untuk pengamatan tingkat kesibukan server diambil waktu tersibuk minggu kedua yaitu tanggal 18 juli-22 juli 2016 penambahahan server dari 4 server menjadi 5-8 server. Pada penambahan server diasumsikan jumlah kedatangan satker tetap dan jumlah satker yang dilayani bertambah sebanyak server yang ditambahkan.

Tabel 6 : Hasil hitung karakteristik antrian dengan melakukan penambahan server

\begin{tabular}{|c|c|c|c|c|c|c|c|c|}
\hline Waktu Pengamatan & $\Lambda$ & M & M & $\begin{array}{c}\rho \\
(\%)\end{array}$ & $\begin{array}{c}\mathrm{Lq} \\
\text { (satker) }\end{array}$ & $\begin{array}{c}\text { Ls } \\
\text { (satker) }\end{array}$ & $\begin{array}{c}\text { Wq } \\
\text { (menit) }\end{array}$ & $\begin{array}{c}\text { Ws } \\
\text { (menit) }\end{array}$ \\
\hline \multirow{4}{*}{ Senin, 18 Juli 2016} & \multirow{4}{*}{10} & 6 & 5 & 33 & 0,02 & 1,68 & 0,09 & 10,09 \\
\hline & & 7 & 6 & 23,8 & 0,001 & 1,43 & 0,007 & 8,578 \\
\hline & & 8 & 7 & 17,86 & 0,0001 & 1,25 & 0,0004 & 7,5004 \\
\hline & & 9 & 8 & 13,89 & 0 & 1,11 & 0 & 6,66 \\
\hline \multirow{4}{*}{ Selasa, 19 Juli 2016} & \multirow{4}{*}{10} & 5 & 5 & 40 & 0,04 & 2,04 & 0,239 & 12,239 \\
\hline & & 6 & 6 & 27,8 & 0,003 & 1,67 & 0,018 & 10,018 \\
\hline & & 7 & 7 & 20,41 & 0,0002 & 1,428 & 0,0011 & 8,57 \\
\hline & & 8 & 8 & 15,63 & 0 & 1,25 & 0,0001 & 7,5 \\
\hline \multirow{4}{*}{ Rabu, 20 Juli 2016} & \multirow{4}{*}{13} & 5 & 5 & 52 & 0,16 & 2,76 & 0,74 & 12,74 \\
\hline & & 6 & 6 & 36 & 0,01 & 2,18 & 0,07 & 10,07 \\
\hline & & 7 & 7 & 26,5 & 0,001 & 1,858 & 0,005 & 8,5 \\
\hline & & 8 & 8 & 20,3 & 0 & 1,62 & 0 & 7,5 \\
\hline \multirow{4}{*}{ Kamis, 21 Juli 2016} & \multirow{4}{*}{15} & 5 & 6 & 50 & 0,13 & 2,63 & 0,6 & 10,8 \\
\hline & & 6 & 7 & 35,7 & 0,014 & 2,156 & 0,06 & 8,64 \\
\hline & & 7 & 8 & 26,8 & 0 & 1,876 & 0,0003 & 7,5 \\
\hline & & 8 & 9 & 20,8 & 0 & 1,667 & 0 & 6,667 \\
\hline \multirow{4}{*}{ Jumat, 22 Juli 2016} & \multirow{4}{*}{14} & 6 & 5 & 46,7 & 0,09 & 2,423 & 0,386 & 10,386 \\
\hline & & 7 & 6 & 33,3 & 0,009 & 2,009 & 0,039 & 8,61 \\
\hline & & 8 & 7 & 25 & 0,001 & 1,75 & 0,003 & 7,503 \\
\hline & & 9 & 8 & 19,4 & 0 & 1,53 & 0 & 6,67 \\
\hline
\end{tabular}

Berdasarkan Tabel 6 dapat diketahui bahwa tingkat kesibukan server setelah penambahan server dari 4 server menjadi 5-8 server mengalami penurunan. Adapun waktu 
paling tersibuk yaitu pada pukul tanggal 21 Juli 2016, terlihat dari banyak satker yang datang $(\lambda)=15$ satker/jam, banyak satker yang dilayani $(\mu)=4$ satker/jam dengan karakteristik antrian sebagai berikut.

\section{Tingkat kesibukan server $(\rho)$}

Tingkat kesibukan server mengalami penurunan dari 75\%(sebelum penambahan server) menjadi $50 \%$ setelah penambahan server menjadi lima server, mengalami penurunan menjadi $35,7 \%$ setelah penambahan server menjadi 6 server, mengalami penurunan menjadi $26,8 \%$ setelah penambahan server menjadi 7 server, mengalami penurunan menjadi $20,8 \%$ setelah penambahan server menjadi 8 server.

2. Banyak satker dalam antrian $(L q)$

Banyak satker yang menunggu dalam antrian mengalami penurunan dari $1,53 \approx 2$ satker/jam menjadi $0,13 \approx 1$ satker/jam setelah penambahan server menjadi 5 server, mengalami penurunan menjadi $0,014 \approx 1$ setelah penambahan server menjadi 6 server, mengalami penurunan menjadi 0 atau tidak ada orang dalam antrian setelah penambahan server menjadi 7-8 server.

3. Banyak satker yang menunggu dalam sistem (Ls)

Banyak satker yang menunggu dalam sistem mengalami penurunan dari $4,53 \approx 5$ satker/jam menjadi $2,63 \approx 3$ satker/jam setelah penambahan server menjadi 5 server, mengalami penurunan menjadi $2,156 \approx 3$ satker/jam setelah penambahan server menjadi 6 server, mengalami penurunan menjadi 1,876 $\approx 2$ satker/jam setelah penambahan server menjadi 7 server, mengalami penurunan menjadi $1,667 \approx 2$ satker/jam setelah penambahan server menjadi 8 server.

4. Waktu yang dihabiskan setiap satker menunggu untuk dilayani (Wq)

Waktu yang dihabiskan satker menunggu untuk dilayani mengalami penurunan dari 6,11 menit menjadi 0,6 menit setelah penambahan server menjadi 5 server, mengalami penurunan menjadi 0,06 menit setelah penambahan server menjadi 6 server, mengalami penurunan menjadi 0,003 menit setelah penambahan server menjadi 7 server, mengalami penurunan menjadi 0 menit atau tidak ada yang antri setelah penambahan server menjadi 8 server.

5. Waktu yang dihabiskan setiap satker untuk menunggu dalam sistem (Ws)

Waktu yang dihabiskan satker menunggu dalam sistem mengalami penurunan dari 18,11 menit menjadi 10,8 menit setelah penambahan server menjadi 5 server, mengalami penurunan menjadi 8,64 menit setelah penambahan server menjadi 6 server, mengalami penurunan menjadi 7,5 menit setelah penambahan server menjadi 7 server, mengalami penurunan menjadi 6,667 menit setelah penambahan server menjadi 8 server. 
Adapun total satker yang terlayani dengan melakukan penambahan server sebanyak 4 server yaitu sebagai berikut.

Dik: $\quad$ Total satker $\left(\mathrm{T}_{\mathrm{s}}\right)=700$ satker, $W_{q}=0, W_{s}=6,667$

1 hari $=8$ jam kerja

1 minggu $=5$ hari jam kerja $=2.400$ menit

Total waktu menunggu $\quad=W_{q}+W_{s}=0+6,667$

$$
=6,667 \text { menit }
$$

Waktu yang dibutuhkan untuk pelaksanaan rekonsiliasi:

$$
\begin{aligned}
& =T_{s} \times T w \\
& =700 \times 6,667 \text { menit } \\
& =4666,9 \text { menit }=77,78 \text { jam } \\
& =9,72 \text { hari atau } 1,94 \text { minggu }
\end{aligned}
$$

Total satker yang terlayani selama 2 minggu

$$
=\frac{2(2.400 \text { menit })}{6,667 \text { menit } / \text { satker }}=719 \text { satker. }
$$

Setelah mengamati sistem antrian dengan melakukan penambahan server, didapatkan solusi penambahan server yang optimal yaitu sebanyak 4 server, hal ini dapat dilihat dari nilai Ws atau waktu yang dihabiskan seorang satker menunggu dalam sistem adalah 6,667 menit dan memenuhi nilai efektif yang diharapkan yaitu $W s \leq 6,85$ menit. Dengan menambahkan 4 server, semua satker yang ingin melakukan rekonsiliasi dapat terlayani dalam waktu yang telah ditentukan yaitu sebanyak 700 satker selama 2 minggu.

\section{KESIMPULAN}

Berdasarkan hasil analisis yang diperoleh pada titik pengamatan di Kantor Pelayanan Kekayaan Negara dan Lelang Palu pelayanan rekonsiliasi Barang Milik Negara(BMN) terbilang sibuk dan hanya dapat melayani satker sebanyak 337 satker dari yang seharusnya dilayani sebanyak 700 satker. Hasil penelitian menunjukkan waktu tersibuk adalah pada tanggal 21 Juli 2016 dan dianalisis dengan melakukan penambahan server sebanyak 1-4 server dan didapatkan hasil yang optimal yaitu penambahan server sebanyak 4 server. Penambahan server dari 4 menjadi 8 server menunjukkan adanya penurunan antrian. Hal ini dapat dilihat dari karakteristik antrian penurunan tingkat kesibukan server $(\rho)$ dari $75 \%$ menjadi $20,8 \%$, banyak satker yang menunggu dalam antrian $\left(L_{q}\right)$ dari $1,53 \approx 2$ satker/jam menjadi 0 satker/jam atau tidak ada yang antri, banyak satker yang menunggu dalam sistem $\left(L_{s}\right)$ dari $4,53 \approx 5$ satker/jam menjadi 1,667 $\approx 2$ satker/jam, waktu menunggu dalam antrian $\left(W_{q}\right)$ dari 6,11 menit menjadi 0 menit atau tidak ada waktu tunggu antrian, waktu menunggu dalam sistem $\left(W_{s}\right)$ dari 18,11 menit menjadi 6,667 menit.Adapun total satker yang terlayani dengan melakukan penambahan server penambahan 4 server yang terlayani adalah seluruh satker yaitu sebanyak 700 satker. 


\section{DAFTAR PUSTAKA}

[1] Handoko, T, H, Manajemen Personalia dan Sumber Daya Manusia, BPFE, 1995, Yogyakarta.

[2] Heizer., Jay., dan Barry Render, Operations Management, Buku 1 Edisi Ke Sembilan, Salemba Empat, 2011, Jakarta.

[3] Prawirosentano, S, Riset Operasi dan Ekonofisika, Bumi Aksara, 2005, Jakarta.

[4] Subagyo, P, Dasar-Dasar Operation Research, BPFE, 2000, Yogyakarta.

[5] Taha, H, Riset Operasi, Edisi Kelima Jilid 2, Binarupa Aksara, 1997, Jakarta. 